\title{
When two equals three: developmental osteology and homology of the caudal skeleton in carangid fishes (Perciformes: Carangidae)
}

\author{
Eric J. Hiltona,* and G. David Johnson ${ }^{b}$ \\ aDivision of Fishes, National Museum of Natural History, Smithsonian Institution, Washington, DC 20560, USA \\ bDivision of Fishes, National Museum of Natural History, Smithsonian Institution, Washington, DC 20560, USA \\ *Author for correspondence (email: ehilton@fieldmuseum.org); Current address: Geology Department, Field Museum, 1400 South Lake Shore Drive, Chicago, IL \\ 606 05, USA.
}

SUMMARY Ontogeny often provides the most compelling evidence for primary homology in evolutionary developmental studies and is critical to interpreting complex structures in a phylogenetic context. As an example of this, we document the ontogenetic development of the caudal skeleton of Caranx crysos by examining a series of cleared and stained larval and postlarval specimens. By studying ontogeny, we are able to more accurately identify some elements of the adult caudal skeleton than is possible when studying the adult stage alone. The presence of two epurals has been used as a synapomorphy of Caranginae (homoplastically present in the scomberoidine genera Scomberoides and Oligoplites). Here we find that three epurals (ep) are present in larvae and small postlarval juveniles (i.e., $<25 \mathrm{~mm}$ standard length [SL]) of
C. crysos and other carangines, but ep2 never ossifies and does not develop beyond its initial presence. Ep2 was last observed in a $33.6 \mathrm{~mm}$ SL specimen as a small nodule of very lightly stained cartilage cells and eventually disappears completely. Therefore, the two epurals present in the adult are ep1 and ep3. In other carangines examined (e.g., Selene, Selar), the rudimentary ep2 ossifies and appears to fuse to the proximal tip of ep1. In these taxa, therefore, the two epurals of the adult appear to be ep1 +2 and ep3. We found no indication of three epurals at any stage in the development of Oligoplites (developmental material of Scomberoides was unavailable). We discuss the osteology of the caudal skeleton of carangoid fishes generally and emphasize the power and importance of ontogeny in the identification of primary homology.
Embryology affords further a test for homologies in contradistinction of analogies.

(Louis Agassiz, Essay on Classification, 1857, p. 86.)

\section{INTRODUCTION}

The importance of ontogeny (Agassiz's “embryology”) for assessing primary homology (sensu de Pinna 1991) has long been recognized (e.g., Huxley 1859) and was recently underscored as a largely untapped source for data in phylogenetic analyses of fishes (Johnson 1993; also see Leis et al. 1997 and articles in Moser et al. 1984). Although ontogeny is only one of several lines of evidence for distinguishing homologies from analogies (others include topographic correspondence and the principle of connectivity; Rieppel and Kearney 2002), it may be one of the most powerful and is certainly one of the most understudied or underutilized. The sequence of ontogenetic events may be useful as phylogenetic character data, although perhaps more significant is the role of ontogeny in identifying the components of a morphological complex. Simply stated, the study of the adult condition alone may be inadequate to conclude that similar conditions reflect common ancestry or vice versa.

The complexity and broad diversity of the skeleton of fishes makes them ideal for the study of ontogeny in relation to phylogeny and functional systems. At the root of understanding this complexity, however, is the accurate establishment of primary homology statements for comparisons. The caudal skeletons of adult teleostean fishes vary widely in their composition and overall anatomy (Whitehouse 1910; Monod 1968; Fujita 1990) and range from taxa in which all elements of the complex remain separate from one another (e.g., Hiodon, Hilton 2002) to those in which nearly all elements fuse together (e.g., Luvarus, Tyler et al. 1989). With the consolidation of individual parts, either through ontogeny or phylogeny, their identification and comparison between taxa may be difficult by studying adult anatomy alone (see Arratia and Schultze 1992). One extreme case of ontogenetic fusion is found in the caudal skeleton of scombroid fishes (tunas and their allies), in which hypurals $1-4$ fuse with the urostyle into 
a single "hypural fan" (Collette and Chao 1975; Potthoff 1975; Potthoff et al. 1986). In the tuna Thunnus atlanticus, as described in detail by Potthoff (1975), the neural arch of preural centrum 2 and epural 1 are also incorporated into the hypural fan, thereby forming a very rigid attachment site for the ligaments and musculature associated with strong swimming.

The caudal skeleton of teleostean fishes is often a rich source for phylogenetically informative characters and is among the first character systems to be examined in osteological studies of fishes. During our ongoing study of the osteology of jacks and their relatives (Carangidae), we discovered an interesting example of the impact that comparative ontogenetic studies may have on the interpretation of phylogenetic patterns in adult morphology. In this article, we document the ontogenetic development of the caudal skeleton of the blue runner, Caranx crysos, based on a series of cleared and stained larval and postlarval specimens as well as dry skeletons of adults. Accordingly we are able to precisely identify some elements of the caudal skeleton of the adult. We also present observations on the development of the caudal skeleton in certain other related taxa and discuss the importance of ontogeny in the study of comparative anatomy.

C. crysos is a member of the family Carangidae, the jacks, pompanos, and trevallies. Carangidae are part of the Carangoidei (Fig. 1), a monophyletic group of percomorph fishes that also includes the roosterfish (Nematistiidae), the remoras (Echeneidae), the cobia (Rachycentridae), and the dolphinfishes (Coryphaenidae). As popular game and food fishes, this is an economically important group of fishes, many of which superficially resemble scombroid fishes (e.g., tunas and mackerels). These fishes have been studied from functional and physiological standpoints (e.g., Grubich 2003) and are the
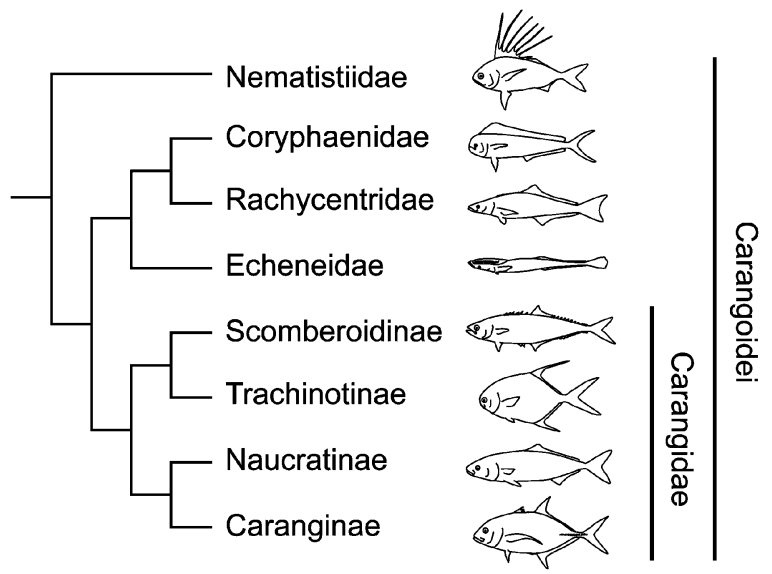

Fig. 1. Hypothesis of the relationships of the major groups of Carangoidei. Relationships of carangid subfamilies following Smith-Vaniz (1984), Gushiken (1988), and Reed et al. (2002). Those of noncarangid families following Johnson (1984) and Smith-Vaniz (1984). nominal model for carangiform locomotion (Breder 1926; Gray 1968). Although there is much information available on the skeletal anatomy of carangoid fishes (e.g., Starks 1911; Suzuki 1962; Smith-Vaniz 1984), their developmental osteology remains poorly known. Few studies have dealt with aspects of the development of the skeleton in carangids, and these have been at varying levels of detail and mostly made before the use of alcian staining of cartilage had come into practice (e.g., Schnakenbeck 1931; Ahlstrom and Ball 1954; Aprieto 1974; Miller and Sumida 1974; Laroche et al. 1984; Liu 2001). External aspects of larval development of C. crysos have been relatively well studied (e.g., McKenney et al. 1958; Berry 1959), but the ontogeny of its skeleton has not. C. crysos was chosen for the developmental component of our study because it is abundant and all life history stages could be well represented in our sample; for many carangid taxa this is not the case. With this article, we hope to reiterate the importance of incorporating ontogenetic information into comparative morphological studies.

\section{MATERIALS AND METHODS}

\section{Preparation, study, and illustration}

Most specimens examined were cleared and stained for bone and cartilage (e.g., Dingerkus and Uhler 1977); some specimens less than $12 \mathrm{~mm}$ standard length (SL) were prepared using an alcoholalizarin solution as recommended by Springer and Johnson (2000). Dry skeletons of adult specimens were prepared by the method of Bemis et al. (2004). Specimens were examined under a binocular Zeiss Stemi SV 11 dissecting microscope with a camera lucida and substage illumination. Illustrations were rendered using Adobe Illustrator software based on camera lucida sketches or digital images taken with a Nikon COOLPIX 8700 coupled to the dissecting microscope.

\section{Specimens examined}

Cleared and stained (c\&s) and dry skeletal (ds) specimens were examined, representing pre- and post-flexion larvae, juveniles, and adults ranging from $2.7 \mathrm{~mm}$ notochord length (NL) to $329 \mathrm{~mm}$ SL. The following specimens of C. crysos were examined: MCZ 64775 (2 c\&s, 9.7-11.9 mm SL); MCZ 84131 (8 c\&s, 5.7-24.7 mm SL); MCZ 84135 (2 c\&s, 6.0-7.6 mm SL); SEAMAP st-568 (1 c\&s, $13.1 \mathrm{~mm}$ SL); SEAMAP s-574 (23 c\&s, $2.7 \mathrm{~mm}$ NL-5.3 mm SL); SEAMAP 1934 (5 c\&s, $3.5 \mathrm{~mm}$ NL $-4.7 \mathrm{~mm} \mathrm{SL}$ ); SEAMAP 17731 (1 c\&s, $18.2 \mathrm{~mm}$ SL); SEAMAP 17747 (4 c\&s, 5.9-7.1 mm SL); SEAMAP 17792 ( 2 c\&s, 6.5-8.9 mm SL); SEAMAP 17788 (5 c\&s, 6.2-9.6 mm SL); SEAMAP 18397 (15 c\&s, $2.3 \mathrm{~mm}$ NL-4.8 mm SL); SEAMAP 18504 (5 c\&s, 4.4-14.9 mm SL); SEAMAP 18513 (1 c\&s, $11.2 \mathrm{~mm}$ SL); SEAMAP 18659 (2 c\&s, 5.7-10.6 mm SL); UMA F11174 (1 ds, $185 \mathrm{~mm} \mathrm{SL})$; UMA F11173 (1 ds, $220 \mathrm{~mm}$ SL); UMA F11596 (1 ds, $250 \mathrm{~mm}$ SL); UMA F10696 (1 ds, 329 mm SL); USNM 158836 (13 c\&s, 10.9-100 mm SL).

Cleared and stained specimens of taxa representing all other carangid genera were also studied, and specimens are cited in the 

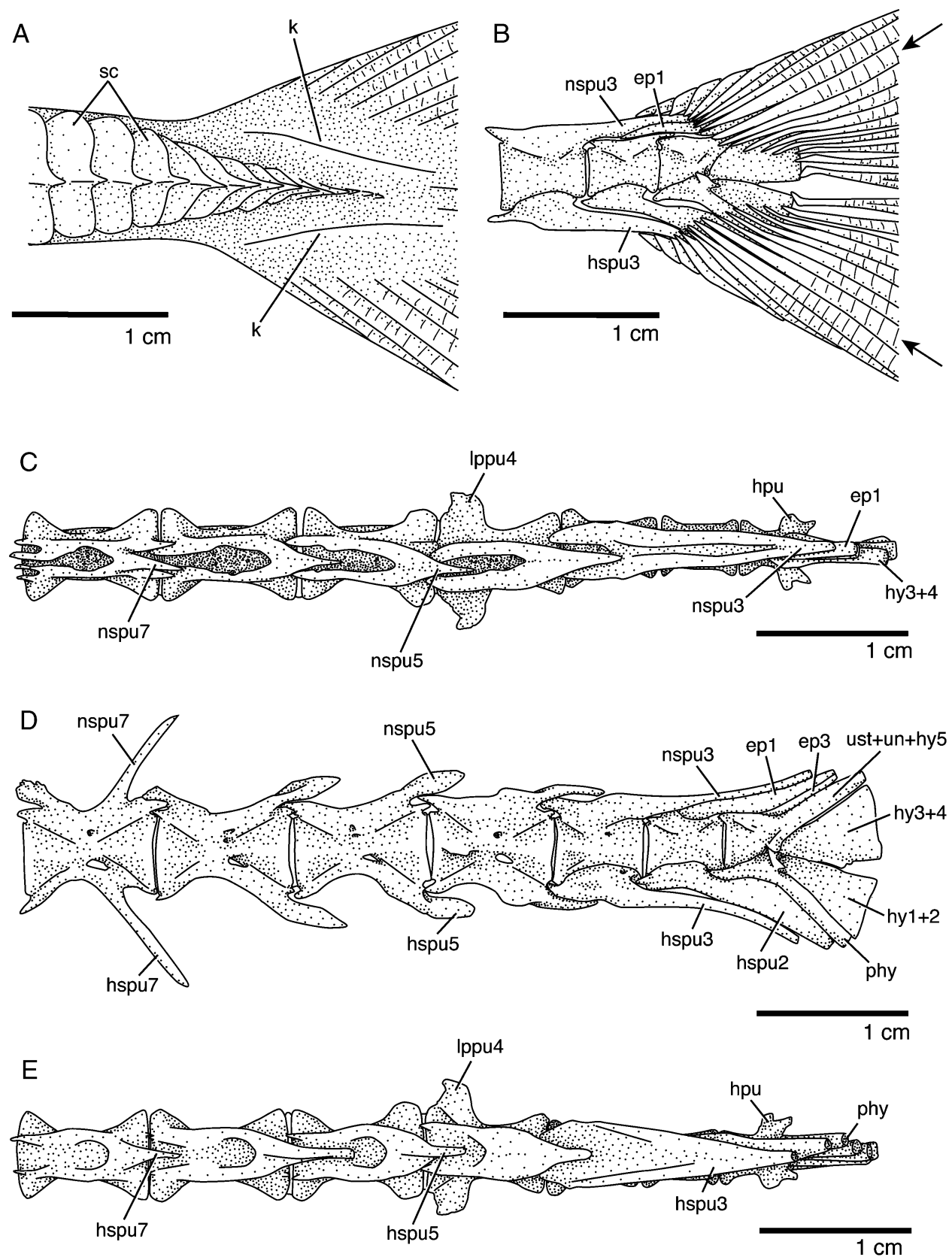

Fig. 2. Adult caudal skeleton of Caranx crysos. (A) External and (B) internal views showing position of scutes and fin rays. (C) Dorsal, (D) lateral, and (E) ventral views of internal caudal skeleton. Scales are omitted from A. Anterior facing left. (A, B) UMA F11174, $185 \mathrm{~mm}$ standard length (SL); (C-E) UMA F11596, $250 \mathrm{~mm} \mathrm{SL}$.

text when relevant to the discussion. This material includes developmental series of the scomberoidine Oligoplites saurus (approximately 40 specimens from $3.8 \mathrm{~mm}$ SL to adults) and the carangine Selene vomer (approximately 30 specimens from $4.1 \mathrm{~mm}$ SL to large adults); both of these series are largely derived from the SEAMAP collection.

\section{Anatomical abbreviations}

der, distal caudal radial; ep, epural; hpu, hypurapophysis; hspu, hemal spine of pu; hy, hypural; $\mathrm{k}$, dorsal and ventral fleshy keels on the lateral surface of the caudal fin; lppu4, lateral process on pu4; nc, notochord; nspu, neural spine of pu; phy, parhypural; pu, preural centrum; sc, scutes; uc, ural centrum; ust, urostylar centrum ( = pul+uc).

\section{Institutional abbreviations}

MCZ, Museum of Comparative Zoology, Harvard University, Cambridge, MA; SEAMAP, Southeast Area Monitoring and Assessment Program Ichthyoplankton Archiving Center, Fish and Wildlife Research Institute, St. Petersburg, FL; 
Fig. 3. Caudal skeleton of Caranx crysos in early stages of development. Anterior facing left. Cartilage is shown in gray, bone in stipple; white stipple indicates light ossification. A, specimen from SEAMAP 18504; (B-D) specimens from MCZ 84131.

\section{A $4.4 \mathrm{~mm} \mathrm{SL}$}

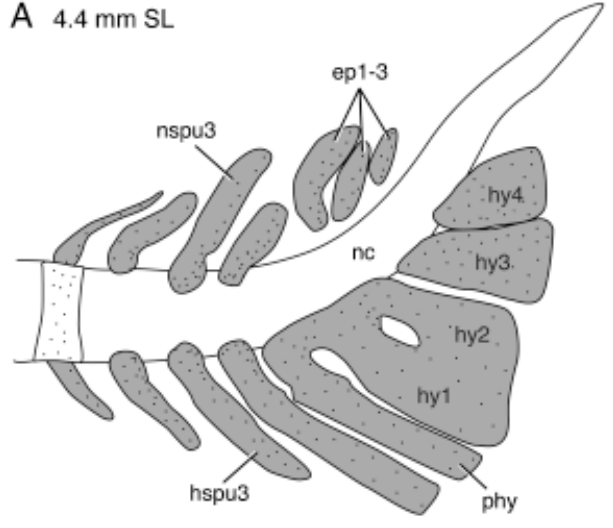

$0.5 \mathrm{~mm}$

C $6.8 \mathrm{~mm} \mathrm{SL}$

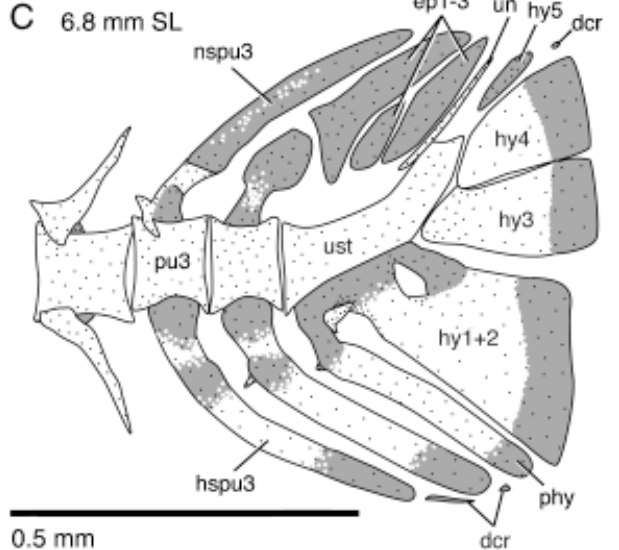

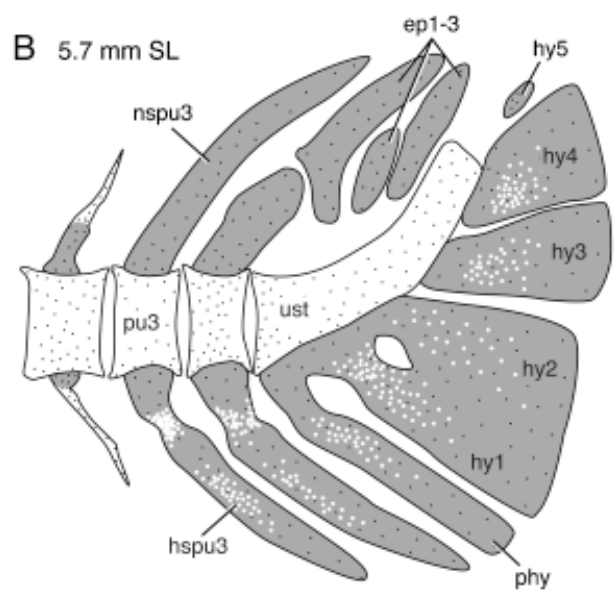

$0.5 \mathrm{~mm}$

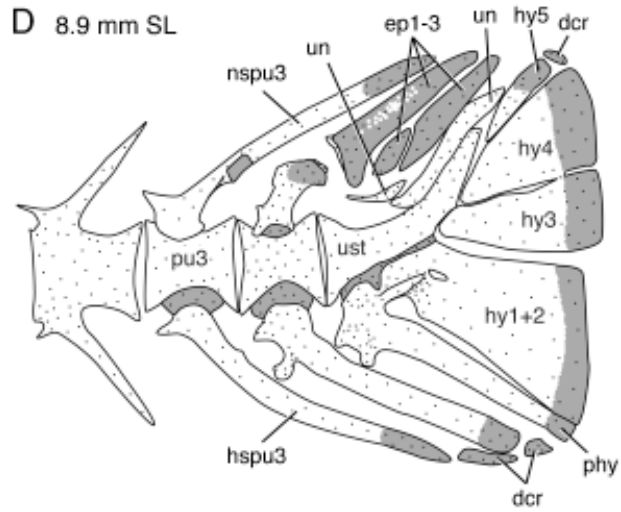

$0.5 \mathrm{~mm}$
UMA, University of Massachusetts Amherst Zoological Collections, Amherst, MA; USNM, United States National Museum of Natural History, Smithsonian Institution, Washington, DC.

\section{RESULTS}

\section{General anatomy of the caudal peduncle and fin supports}

Berry (1960) described and illustrated the development of the scutes and scales of $C$. crysos, including those of the caudal peduncle, and their development will not be described here as our findings generally agree with his. We do provide a brief description of the general adult anatomy of this region as a reference for our study of the caudal skeleton. The posterior portion of the adult caudal region is illustrated in Fig. 2. Externally, it bears a series of thick overlapping scutes, which are particularly deep and robust in the region posterior to pu4 and form a well-developed lateral keel on the caudal peduncle (Fig. 2A). Posteriorly, the scutes decrease in size, and the series terminates at about the level of the posterior margin of the hypurals. Extending onto the caudal fin are fleshy but rigid lateral keels dorsal and ventral to the scutes, which greatly stiffen the central portion of the deeply forked caudal fin. The dorsal and ventral caudal fin rays deeply embrace the endoskeletal supports (Fig. 2B), and small unsegmented procurrent fin rays extend the caudal fin anteriorly to about the middle of the centrum of pu2. The skeletal supports of the caudal fin of C. crysos, like those of other carangids, involve vertebrae posterior to and including pu3.

\section{Vertebral centra}

Ossification of centra progresses rostrocaudally. By $3.5 \mathrm{~mm}$ NL the centra of the immediate preural region are ossified as very thin, smooth rings of bone. The compound urostylar centrum $(=\mathrm{pu} 1+\mathrm{uc})$ is bent dorsally, as it follows the curve of the notochord (Fig. 3, B-D) and ossifies as a single element by $4.7 \mathrm{~mm} \mathrm{SL}$. In later stages, this centrum is fused to the uroneural and hypural 5 (Figs. 2D and 4D). Lateral struts on the centra are evident by $25.2 \mathrm{~mm}$ SL (e.g., Fig. 4D). 

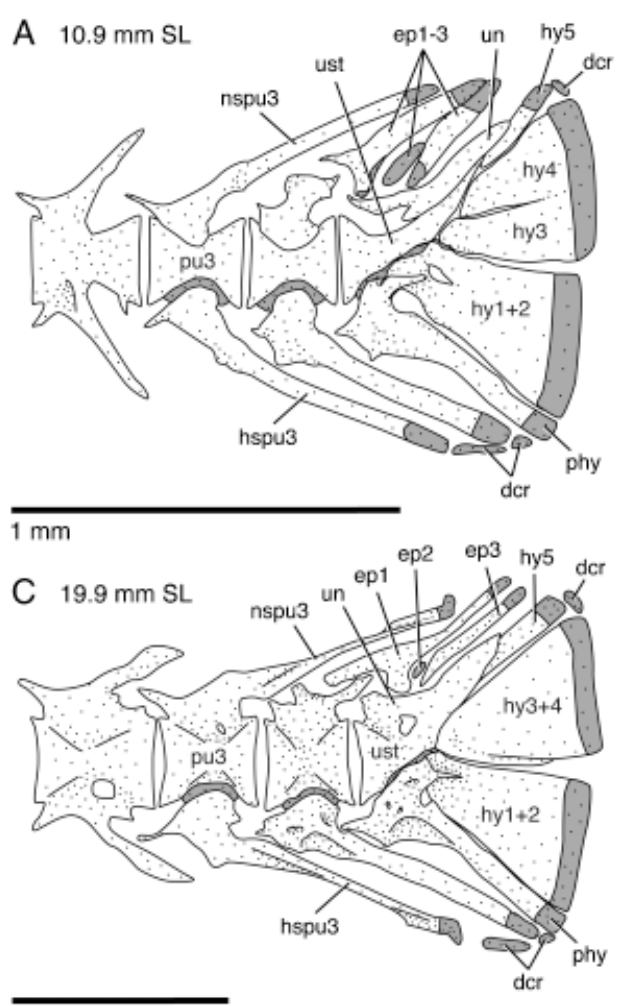

$1 \mathrm{~mm}$

\section{B $14.9 \mathrm{~mm} \mathrm{SL}$}

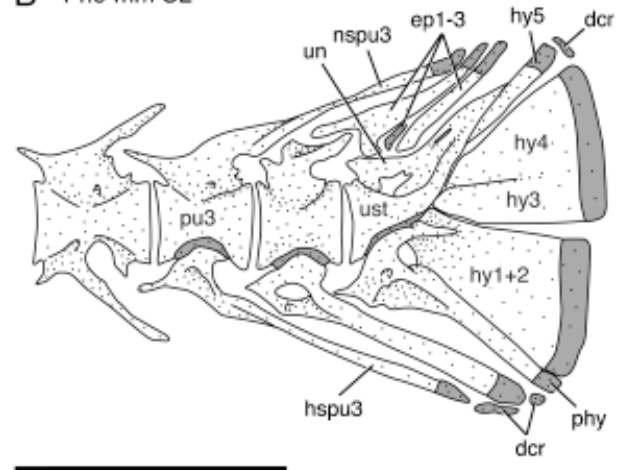

$1 \mathrm{~mm}$

D $25.2 \mathrm{~mm} \mathrm{SL}$

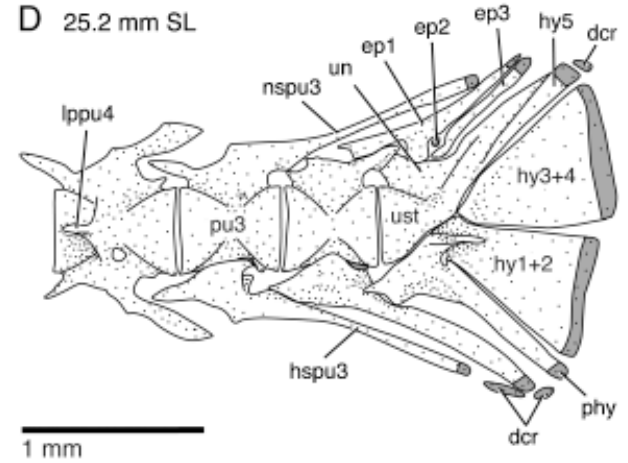

Fig. 4. Caudal skeleton of Caranx crysos in various stages of larval and post-larval development in lateral view. Anterior facing left. Cartilage is shown in gray, bone in stipple; white stipple indicates light ossification. (A-D) specimens from USNM 158836.
A prominent lateral process on pu4 (Fig. 2, C and E) is well developed by $25.2 \mathrm{~mm}$ SL.

\section{Parhypural and hypural series}

The hypochordal elements of the caudal skeleton include the parhypural (phy) and five hypurals (hy1-5). The smallest specimens available did not stain well (not illustrated), but the phy, hy1, and hy 2 are present by $3.3 \mathrm{~mm}$ NL; hy3 and hy4 are also present by $3.8 \mathrm{~mm} \mathrm{NL}$ (at this stage, hy4 is not well developed, although its proximal margin is well defined). The phy, hy1, and hy2 are fused proximally early in ontogeny (Fig. 3A): in a $4.3 \mathrm{~mm}$ NL specimen, hy1 and hy2 are fused and the phy is fused to hy $1+2$ proximally although it remains separate for most of its length. The smallest well-stained specimen $(4.6 \mathrm{~mm} \mathrm{NL})$ is an early post-flexion larva. Although the elements are continuous proximally in this and other specimens of a comparable stage, there are distinct separations between the phy and hy1, and hyl and hy2. In later stages (by $4.4 \mathrm{~mm}$ SL; Fig. 3A), hy1 and hy2 are fused distally and, when hy1 and hy2 become more completely formed, there is a distinct fenestra marking the boundary between the two hypurals. This large fenestra is present in the proximal portion of hyl +2 (e.g., Figs. 3 and 4) and becomes progressively smaller as the hypurals ossify along its distal margin (Fig. 5, A-C). It is still present in a $19.5 \mathrm{~mm}$ SL specimen but disappears by $25.2 \mathrm{~mm}$ SL (in Fig. 4, B and C, the fenestra is hidden by the hypurapophysis). Hypural 3 and hy4 are completely separate in a $9.7 \mathrm{~mm}$ SL specimen but are fused distally in a $10.9 \mathrm{~mm}$ SL specimen; they are completely fused by $25.2 \mathrm{~mm}$ SL.

Hypural 5 is the smallest of the series and is the last to develop. It was first seen in $5.7 \mathrm{~mm}$ SL larvae (MCZ 84131, SEAMAP 18659) as a small cartilage positioned along the dorsal margin of hy4 (Fig. 3B); ossification was first detected in a $7.2 \mathrm{~mm}$ SL specimen. Hypural 5 gradually elongates and becomes positioned between the dorsal margin of hy4 and the urostyle (e.g., Fig. 3D) and remains autogenous until at least $15.5 \mathrm{~mm}$ SL, but eventually fuses to the urostyle (e.g., Fig. 4D). In the adult, there is a groove indicating the boundary between the two elements, but they cannot be separated and the groove is indistinct proximally.

\section{Epurals (ep)}

Three epurals (ep1-3) are present in larvae and small (i.e., $<25 \mathrm{~mm}$ SL) postlarval juveniles (Figs. 3-5). The ep appear anterior to posterior and in the earliest stages decrease in size anterior to posterior (Fig. 3A). In slightly later stages ep1 and ep3 become the largest, with ep2 being about half their length (e.g., Fig. 3B). All three epurals are present by $4.2 \mathrm{~mm}$ NL. Epural 1 bears an anterior projection that is recognizable 

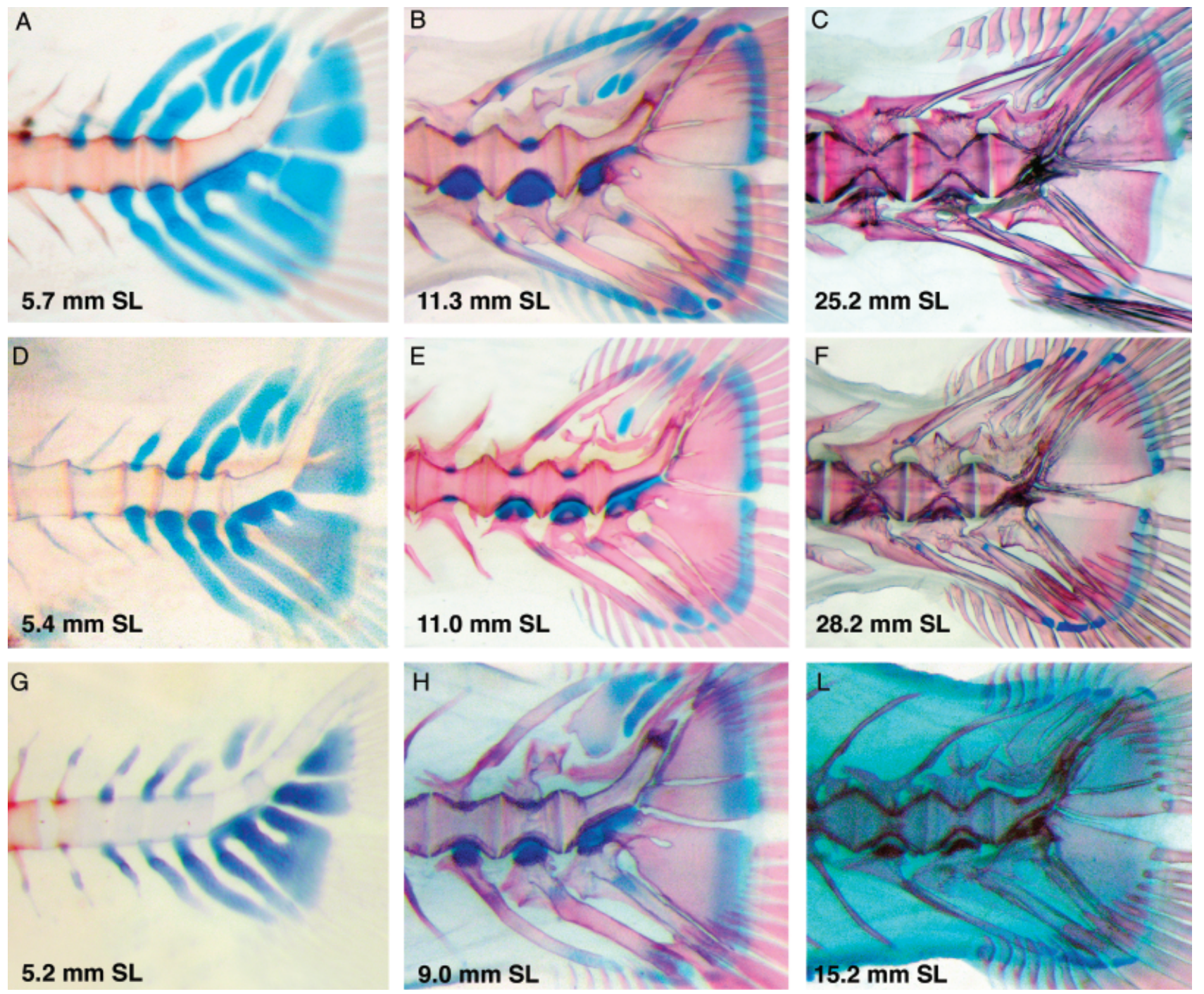

Fig. 5. Caudal skeleton of carangid fishes at various stages of development. (A-C) Caranx crysos (MCZ 84131, SEAMAP 18504, and USNM 158836, respectively). (D-F) Selene vomer (SEAMAP 26870, SEAMAP 26881, and USNM 383080, respectively). (G-I) Oligoplites saurus (SEAMAP 29375, SEAMAP 16618, and SEAMAP 17031, respectively). Anterior facing left.

early in ontogeny (Fig. 3B) and continues to grow anteriorly so that it becomes intercalated between the rudimentary neural spine of pu2 (nspu2) and nspu3 (Fig. 4). Epural 2 does not appear to develop further after its initial appearance and eventually disappears. It was last detected in a $33.6 \mathrm{~mm}$ SL specimen (USNM 158836) as a small nodule of very lightly stained cartilage cells positioned between the proximal portions of ep1 and ep3; in a $40.3 \mathrm{~mm}$ SL specimen from the same lot there was no space between ep1 and ep3 and no trace of ep2.

\section{Uroneural}

The paired dermal uroneurals are the last elements of the caudal skeleton to develop and were first found in a $6.6 \mathrm{~mm}$
SL specimen as thin splints of bone lying dorsal and lateral to the notochord posterior to ep3 (e.g., Fig. 3C). These splints grow anteriorly, ventral to the epural (ventral to ep2 by $7.0 \mathrm{~mm} \mathrm{SL}$ and ventral to ep1 by $8.0 \mathrm{~mm} \mathrm{SL}$ ). The uroneurals were first found to be fused posteriorly to the urostylar centrum at $14.9 \mathrm{~mm}$ SL (Fig. 4B) but become fused to the urostylar centrum along their entire ventral margins in later stages (e.g., Fig. 4, C and D). In an $8.9 \mathrm{~mm}$ SL specimen (MCZ 84131), a second more anterior uroneural was found lying along the proximal tips of the epurals on both sides of the specimen (Fig. 3D). This specimen is considered anomalous, as an autogenous second pair of uroneurals was not observed in any other specimen. It is possible that the uroneural of later stages is actually best regarded as un $1+2$ (as in 
Coryphaena, Potthoff 1975), but this hypothesis requires more data.

\section{Neural and hemal elements of preural skeleton}

The neural and hemal spines of pu2 and pu3 are distinct from more anterior ones. Early in ontogeny they are very thick cartilaginous structures, whereas the more anterior neural and hemal spines are much more slender (e.g., Fig. 3B). On the vertebrae that support the caudal fin, the neural and hemal arches ossify separately from their respective spines (e.g., Fig. 3, B and C) but become continuous soon after ossification (e.g., Fig. 3D). The nspu2 is always rudimentary even at first development (e.g., Fig. 3A) and disappears in the adult (e.g., Fig. 2D).

\section{Distal caudal radials}

The elongate distal caudal radial (= post-hypural cartilage and post-hemal spine cartilages of Fujita 1990) associated with hspu3 is the largest; it was first detected in a $5.7 \mathrm{~mm}$ SL specimen (e.g., SEAMAP 18659; although see Fig. 3B), and it is well developed by $6.2 \mathrm{~mm}$ SL (SEAMAP 17788). Two additional spherical cartilages are associated with the distal tips of hy5 and hspu2 and were first found in a $6.6 \mathrm{~mm} \mathrm{SL}$ specimen (SEAMAP 17788).

\section{DISCUSSION}

\section{Variation of the caudal skeleton of Carangoidei}

The adult caudal skeleton of carangoid fishes shows a wide variety of patterns. Rosenblatt and Bell (1976: figs. 10, 11) figured the caudal skeleton of Nematistius. In the adult (represented in their figures by a large juvenile) there are three independent epurals (ep2 and ep3 are equal in length), two uroneurals (both of which remain autogenous from pu1+uc), a parhypural, and three hypurals (their hy1 +2 , hy3 +4 , hy5). Potthoff (1980: 298) described the caudal complex of adult Coryphaena as comprising "two hemal spines, a parhypural, a ventral, and dorsal hypural plate [each formed by ontogenetic fusion of two hypurals], hypural 5, a uroneural pair (fused from two pairs), and an epural (fused from two)," the neural spines of pu2 and pu3, and the three associated centra (pu2, pu3, and ust).

Rachycentron and echeneids have five independent hypurals, whereas Coryphaena and carangids have three distinct hypurals, representing hy $1+2$, hy $3+4$, and hy 5 in taxa for which the ontogeny has been studied (e.g., Potthoff 1980; Fujita 1990, also personal observation). In carangids, hy5 becomes tightly enveloped by the uroneural dorsally, and the posterior extension of the urostylar centrum laterally. Hypural 5 remains autogenous in most carangids but may become fused to the compound urostylar centrum-uroneural. The taxonomic distribution of this fusion needs further study, but it was not observed in noncarangine carangids (e.g., Naucrates, Elagatis, Trachinotus, Oligoplites; personal observation, also taxa illustrated by Hollister, Monod, Fujita, and others). Similarly, fusion between the uroneural and the urostylar centrum was only observed in carangines.

There have been many previous descriptions and illustrations of the caudal skeleton of carangids [Scomberoidinae: Scomberoides and Parona (Smith-Vaniz and Staiger 1973); Trachinotinae: Trachinotus (Hollister 1941; Monod 1968; Fujita 1990); Naucratinae: Seriola and Elagatus (Berry 1969; Fujita 1990; Liu 2001); Caranginae: Decapterus, Alectis, Selene, Trachurus, Caranx, Selar, and Chloroscombrus (Hollister 1941; Monod 1968; Fujita 1990; Suda 1996)]. Within the family Carangidae the caudal skeleton is remarkably constant, although there is subtle variation in various fusion patterns and number of elements in the subfamily Caranginae (Table 1).

\section{Loss versus fusion of epurals}

Perhaps the most interesting variation in the carangid caudal skeleton that we discovered during this study is in the number of epurals (Table 1). Nematistius has three epurals (Rosenblatt and Bell 1976), as do echeneids and Rachycentron (e.g., Fujita 1990, also personal observation). Potthoff (1980) demonstrated that the single epural of Coryphaena is the product of fusion of two independent epurals during ontogeny. In all noncarangine genera (i.e., Trachinotinae, Scomberoidinae,

Table 1. Some characters in the caudal skeletal anatomy of carangoid fishes

\begin{tabular}{lccc}
\hline Taxon & $\begin{array}{c}\text { Number of } \\
\text { epurals (in adult) }\end{array}$ & $\begin{array}{c}\text { Unfused } \\
\text { to ust }\end{array}$ & $\begin{array}{c}\text { hy5 fused } \\
\text { to ust }\end{array}$ \\
\hline $\begin{array}{l}\text { Nematistiidae } \\
\text { Coryphaenidae }\end{array}$ & 3 & No & No \\
$\begin{array}{l}\text { Rachycentridae } \\
\text { Echeneidae }\end{array}$ & 1 & No & No \\
Carangidae & 3 & No & No \\
$\begin{array}{l}\text { Scomberoidinae } \\
\text { Trachinotinae }\end{array}$ & 2 or 3 & No & No \\
Naucratinae & 3 & No & No \\
Caranginae & 3 & No & No \\
\hline
\end{tabular}

${ }^{1}$ For ease of use with our discussion, we here list the genera included in the families and subfamilies of Carangoidei, following Smith-Vaniz (1984).

Nematistiidae: Nematistius. Coryphaenidae: Coryphaena. Rachycentridae: Rachycentron. Echeneidae: Echeneis, Phtherichthys, Remora, Remorina. Carangidae: Scomberoidinae: Oligoplites, Parona, Scomberoides; Trachinotinae: Lichia, Trachinotus; Naucratinae: Campogramma, Elagatis, Naucrates, Seriola, Seriolina; Caranginae: Alectis, Alepes, Atule, Atropus, Carangichthys, Carangoides, Caranx, Chloroscombrus, Decapterus, Gnathanodon, Hemicaranx, Megalaspis, Pantolabus, Parastromateus, Pseudocaranx, Selar, Selaroides, Selene, Trachurus, Ulua, Uraspis. ust, urostylar centrum. 
Fig. 6. Caudal skeleton of Selene vomer at four developmental stages. (A) SEAMAP 26881. (B) USNM 383080. (C) USNM 383081. (D) UMA F10936. Anterior facing left. Cartilage is shown in gray, bone in stipple.

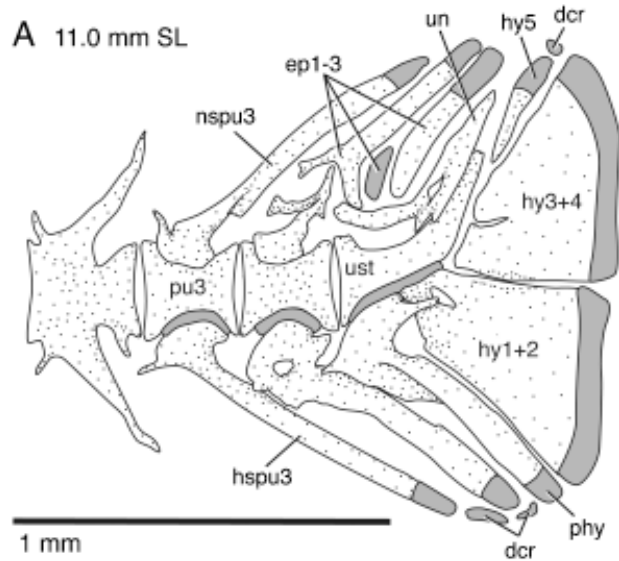

B $28.2 \mathrm{~mm} \mathrm{SL}$
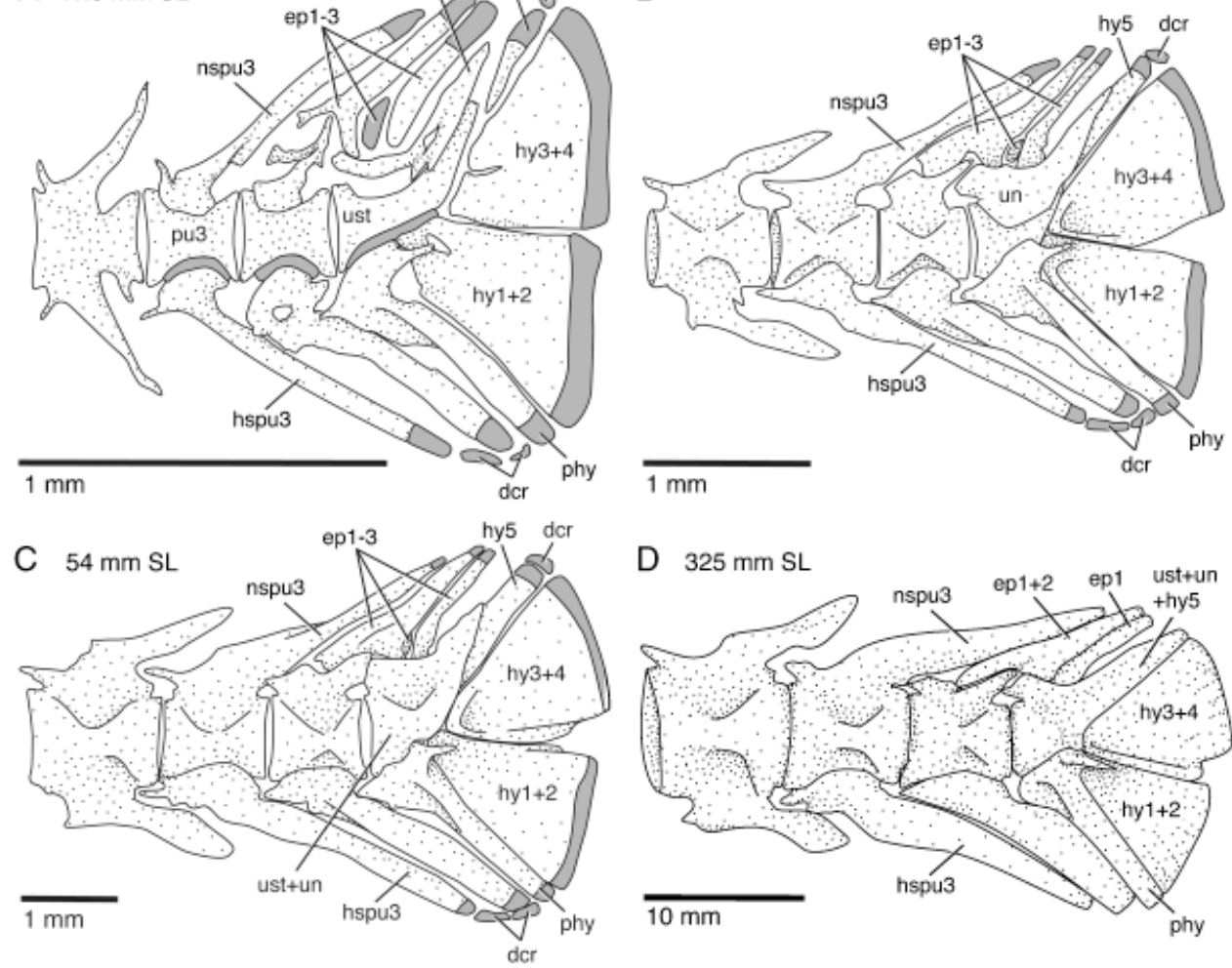

D $325 \mathrm{~mm} \mathrm{SL}$
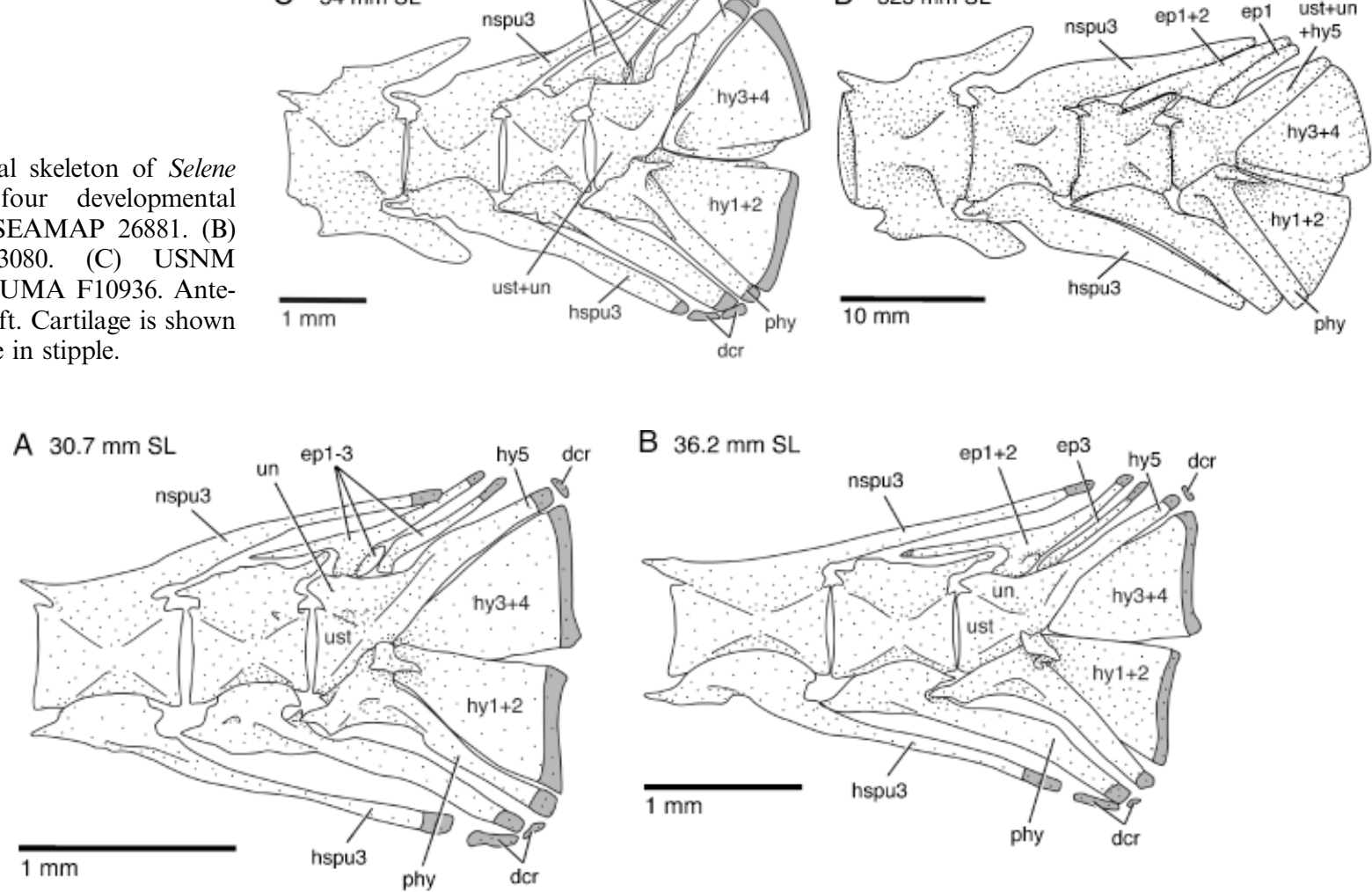

B $36.2 \mathrm{~mm} \mathrm{SL}$

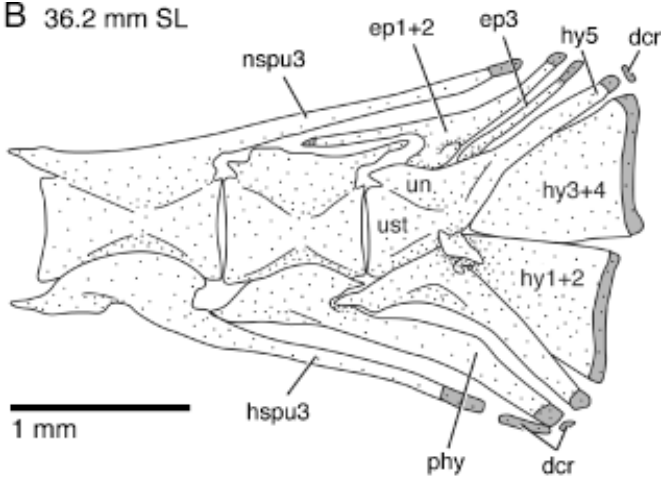

Fig. 7. Caudal skeleton of Selar crumenophthalmus (all from MCZ 149687). Dashed line in C indicates the outline of the inclusion of ep 2 in the compound ep1 1 2. Anterior facing left. Cartilage is shown in gray, bone in stipple.

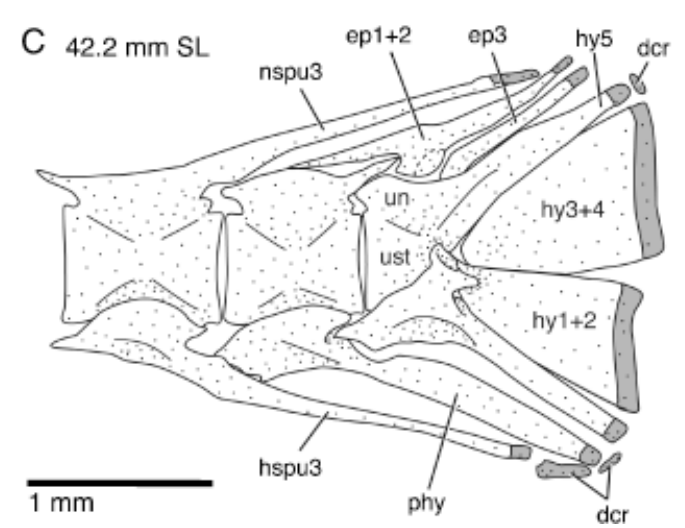



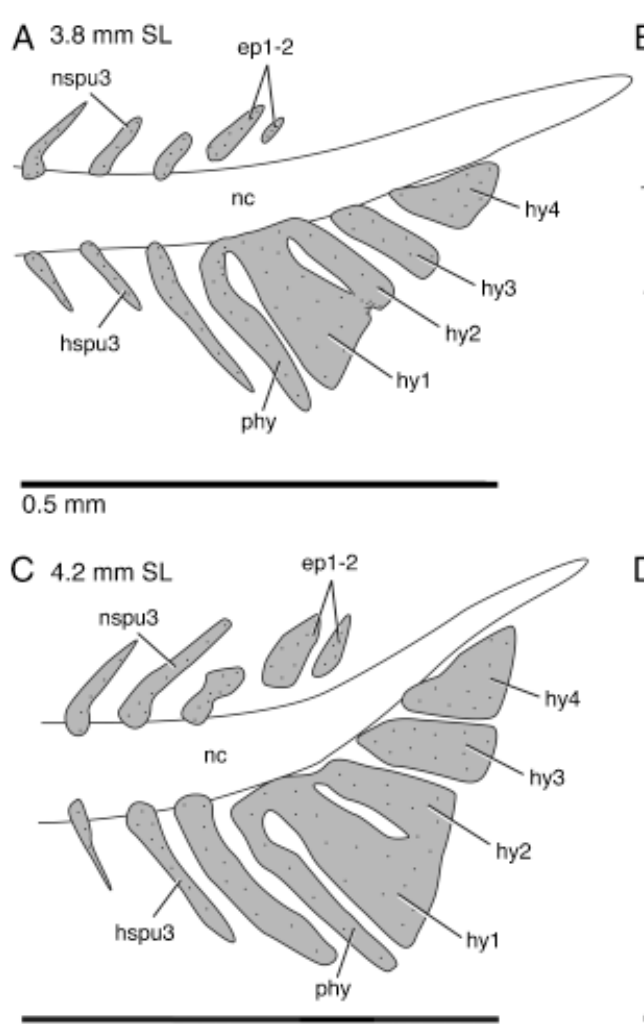

$0.5 \mathrm{~mm}$
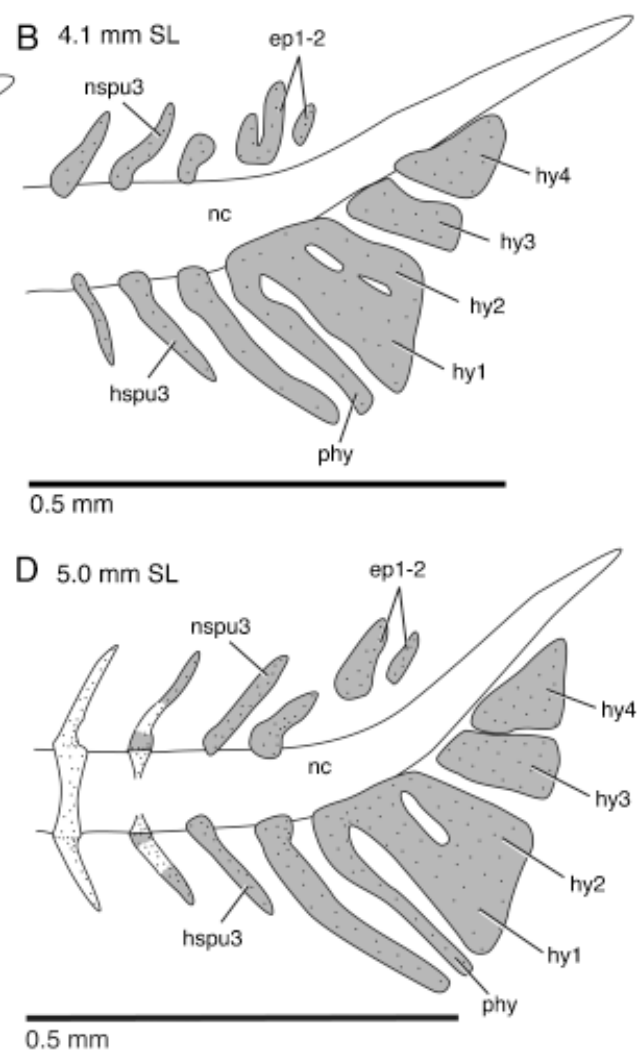

Fig. 8. Caudal skeleton of Oligoplites saurus in early stages of development. (A, B, and C) from SEAMAP 29375. (D) from SEAMAP 16618. Anterior facing left. Cartilage is shown in gray, bone in stipple. and Naucratinae) except for the scomberoids Scomberoides and Oligoplites, there are three epurals (Smith-Vaniz 1984: table 127). Based on the current understanding of the interrelationships of carangoid fishes (Fig. 1), it can be concluded that three epurals is plesiomorphic for the family Carangidae. Adults of all genera of the subfamily Caranginae have only two epurals, and Smith-Vaniz (1984) considered this to be a synapomorphy of the group (independently derived in the scomberoids Scomberoides and Oligoplites). However, he did not identify which epurals are present in carangines and the two scomberoidine genera, only that there are two rather than three.

We have documented here the ontogenetic loss of ep2 in $C$. crysos and thus can identify the two epurals present in the adult as ep1 and ep3. In examining comparative material, we discovered that larval and small juvenile specimens of Selene vomer also have a third epural (ep2) similar in form to that of small specimens of $C$. crysos (i.e., a short bar of cartilage; Figs. 5D and 6A) but ossified (Figs. 5, E, F and 6, B, C). Larger specimens (i.e., in the adult condition) have only two epurals (Fig. 6D). We observed a similar ossified ep2 in small (i.e., juvenile) specimens of the carangines Selar crumenophthalmus (MCZ 149687, 30.7-56.4 mm SL; Fig. 7), Chloroscombrus chrysurus (USNM 383076, 18.4-26.7 mm SL; USNM 383077, 54-62 mm SL), and Gnathanodon speciosus
(USNM 383087, $86 \mathrm{~mm}$ SL). Larval $T$. trachurus have three epurals (Schnakenbeck 1931) and Witzell (1977: Fig. 7) figured a similar arrangement in a juvenile specimen of Parastromateus niger, as did Fujita (1990: figs. 295, 297 respectively) in Caranx ignobilis and Alectis ciliaris. In larger specimens of these and other carangine taxa, there are only two epurals (e.g., Fig. 6D; also see Trachurus japonicus and Caranx equula, Fujita 1990: figs. 294, 296, respectively).

Further detailed study of the development of the caudal skeleton in carangines is necessary. Although our limited series of the carangine Selene vomer does not demonstrate the actual fusion of ep2 to ep1, it strongly suggests that such fusion occurs, a condition different from that in C. crysos, in which ep2 is lost. This hypothesis gains support (albeit through circumstantial evidence) from our observation of two specimens of Selar, also a carangine, in which ep1 and ep2 are fused (MCZ 14968; $36.2 \mathrm{~mm} \mathrm{SL}$ and $42.2 \mathrm{~mm}$ SL; Fig. 7). In the $42.2 \mathrm{~mm}$ SL specimen (Fig. 7C) the two are completely fused, but an inclusion in the bone of the anteriormost epural that is the exact shape and position of an autogenous ep2 in other specimens can be detected with transmitted light. There is some individual variation in fusion, as the two epurals are clearly separate in the largest specimen of this lot $(56.4 \mathrm{~mm}$ $\mathrm{SL})$. In the $70 \mathrm{~mm}$ specimen of $T$. trachurus illustrated by 
Fig. 9. Caudal skeleton of Oligoplites saurus in various stages of larval and postlarval development. (A, B) from SEAMAP 16618. (C) from USNM 383078. (D) USNM 383079. Anterior facing left. Cartilage is shown in gray, bone in stipple.

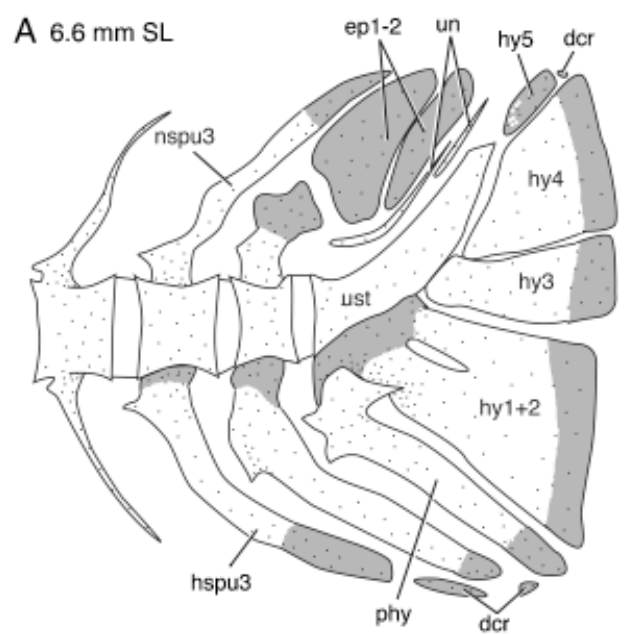

B $9.0 \mathrm{~mm} \mathrm{SL}$


$0.5 \mathrm{~mm}$

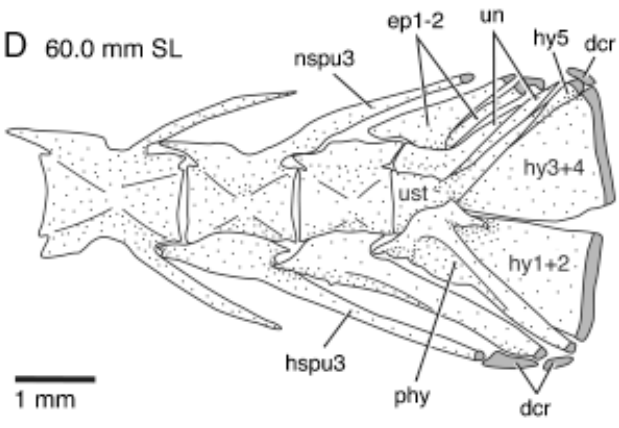

Schnakenbeck (1931: Fig. 3f), ep2 appears to be continuous with ep1. In taxa in which ep2 ossifies, it may persist as an autogenous element in relatively large individuals (e.g., the $150 \mathrm{~mm}$ SL specimen of Alectis ciliaris illustrated by Fujita 1990: fig. 297).

The question then arises, "What is the ontogenetic trajectory in the scomberoidines that also have two epurals in the adult (i.e., Oligoplites and Scomberoides)?" Larval material of Scomberoides was not available to us and there is no data on its development in the literature. In the larval and postlarval specimens of $O$. saurus we examined, there is no trace of a third epurals at any stage (Figs. 8 and 9). The anteriormost epural is always larger than ep2 but becomes much broader in juveniles and adults than in larvae. The general pattern of development was found to be consistent within our series, with only a few minor variations noted. For example, in a few specimens ep1 is roughly $\mathrm{J}$-shaped (Fig. 8B), although the anterior portion of this element was not found to be autogenous in either smaller or larger specimens (e.g., Fig. 8, A and C). A small postlarval specimen of $O$. saurus (USNM 383088, $13 \mathrm{~mm} \mathrm{SL}$ ) has an anomalous condition of a single epurals, which is likely the fusion of two epurals. We conclude that the two epurals of the scomberoidine and carangine genera do not represent similar conditions even though a similar pattern is found in adults of the two groups. However, it should be noted that ep1 of Oligolplites is not necessarily equivalent to that of Caranx or other carangines.

\section{CONCLUSION}

Reduction in the number of discrete elements through ontogeny may occur by fusion, where adjacent elements become inseparable from one another, or by loss, where an element initially forms but disappears through resorption. Both mechanisms result in a similar configuration but are fundamentally different in that they reflect different ontogenetic trajectories. Our example from the development of the caudal skeleton of carangids further demonstrates the importance of ontogeny in formulating primary homology statements and in character conceptualization, and the potential fallacy of a priori assumptions about phylogenetic or ontogenetic fusion or loss (see discussions by Nelson 1969; Patterson 1977; Donoghue 2002; Hilton 2002; and Britz and Johnson 2003, 2005).

Although beyond the scope of this project, a broader taxonomic comparison of the development of the caudal skeleton within carangines may reveal additional patterns of ontogenetic variation, possibly reflective of phylogenetic 
patterns. It is clear that the two epurals of adult Scomberoides and Oligoplites are not entirely comparable with those of Caranginae. There have been recent advances in the study of phylogenetic systematics of Carangidae (e.g., Reed et al. 2002). However, a better understanding of the relationships within Carangidae, in particular among the genera in the subfamily Caranginae (e.g., more complete taxon sampling), is necessary before the true significance of the variation in ontogenetic trajectories can be fully assessed. The different ontogenetic trajectories arriving at similar adult conditions described herein may also be reflective of different gene expression patterns, and as such, carangid fishes may offer a useful model system for both evolutionary and developmental approaches to understanding anatomy.

\section{Acknowledgments}

We thank M. Leiby and K. Williams (SEAMAP) for making available most of the early stages of the developmental series, indeed most of the specimens, used in this project. We also thank K. Hartel (MCZ) and W. E. Bemis (UMA) for access and permission to prepare specimens in their care. W. F. Smith-Vaniz and V. G. Springer offered encouragement and suggestions with our study of carangid osteology. R. Britz, V. G. Springer, and two anonymous reviewers offered helpful suggestions on a previous version of this manuscript. This research was conducted while E. J. H. was supported by a Smithsonian Institution Postdoctoral Fellowship in the Department of Zoology, for which he is grateful.

\section{REFERENCES}

Agassiz, L. 1857. Contributions to the Natural History of the United States of America. First Monograph. In Three Parts.-I. Essay on Classification.-II. North American Testudinata.-III. Embryology of the Turtle; with ThirtyFour Plates. 1. Little, Brown and Company, Boston.

Ahlstrom, E. H., and Ball, O. P. 1954. Description of eggs and larvae of jack mackerel (Trachurus symmetricus) and distribution and abundance of larvae in 1950 and 1951. Fish. Bull. 56: 207-245.

Aprieto, V. L. 1974. Early development of five carangid fishes of the Gulf of Mexico and the south Atlantic coast of United States. Fish. Bull. 72: 415-443.

Arratia, G., and Schultze, H.-P. 1992. Reevaluation of the caudal skeleton of certain actinopterygian fishes. III. Salmonidae. Homologization of caudal skeletal structures. J. Morphol. 214: 187-249.

Bemis, W. E., et al. 2004. Methods for preparing dry, partially articulated skeletons of osteichthyans, with notes on making ridewood dissections. Copeia 2004: 603-609.

Berry, F. H. 1959. Young jack crevalles (Caranx species) off the southeastern Atlantic Coast of the United States. Fish. Bull. 152: 417-535.

Berry, F. H. 1960. Scale and scute development of the carangid fish Caranx crysos (Mitchill). Quart. J. Florida Acad. Sci. 23: 59-66.

Berry, F. H. 1969. Elagatis bipinnulata (Pisces: Carangidae): morphology of the fins and other characters. Copeia 1969: 454 463.

Breder, C. M. 1926. The locomotion of fishes. Zoologica 4: 159-297.

Britz, R., and Johnson, G. D. 2003. Paradox lost: skeletal ontogeny of Indostomus paradoxus and its significance for the phylogenetic relationships of Indostomidae (Teleostei, Gasterosteiformes). Am. Mus. Nov. 3383: 1-43.

Britz, R., and Johnson, G. D. 2005. Leis' conundrum: homology of the clavus of the ocean sunfishes. 1. Ontogeny of the median fins and axial skeleton of Monotrete leiurus (Teleostei, Tetraodontiformes, Tetraodontidae). J. Morphol. 266: 1-10.
Collette, B. B., and Chao, L. 1975. Systematics and morphology of the bonitos (Sarda) and their relatives (Scombridae, Sardini). Fish. Bull. 73: 516-625.

de Pinna, M. C. C. 1991. Concepts and tests of homology in the cladistic paradigm. Cladistics 7: 367-394.

Dingerkus, G., and Uhler, L. D. 1977. Enzyme clearing of alcian blue stained whole small vertebrates for demonstration of cartilage. J. Stain Technol. 52: 229-232.

Donoghue, P. C. J. 2002. Evolution of development of the vertebrate dermal and oral skeletons: unraveling concepts, regulatory theories, and homologies. Paleobiology 28: 474-507.

Fujita, K. 1990. The Caudal Skeleton of Teleostean Fishes. Tokai University Press, Tokyo.

Gushiken, S. 1988. Phylogenetic relationships of the perciform genera of the family Carangidae. Jap. J. Ichthyol. 34: 443-461.

Gray, J. 1968. Animal Locomotion. Weidenfeld and Nicolson, London.

Grubich, J. 2003. Morphological convergence of pharyngeal jaw structure in durophagous perciform fish. Biol. J. Lin. Soc. 80: 147-165.

Hilton, E. J. 2002. Osteology of the extant North American fishes of the genus Hiodon Lesueur 1818 (Teleostei: Osteoglossomorpha: Hiodontiformes). Fieldiana (Zool.), n. ser. 100: 1-142.

Hollister, G. 1941. Caudal skeleton of Bermuda shallow water fishes. V. Order Percomorphi: Carangidae. Zoologica 26: 31-45.

Huxley, T. H. 1859. Observations on the development of some parts of the skeleton of fishes. Quart. J. Microscop. Sci. 7: 33- 46.

Johnson, G. D. 1984. Percoidei: development and relationships. In H. G. Moser, W. J. Richards, D. M. Cohen, M. P. Fahay, A. W. Kendall Jr., and S. L. Richardson (eds.). Ontogeny and Systematics of Fishes. ASIH/ Allen Press, Lawrence, pp. 464 498.

Johnson, G. D. 1993. Percomorph phylogeny: progress and problems. Bull. Mar. Sci. 52: 3-28.

Laroche, W. A., Smith-Vaniz, W. F., and Richardson, S. L. 1984. Carangidae: development. In H. G. Moser, W. J. Richards, D. M. Cohen, M. P. Fahay, A. W. Kendall Jr., and S. L. Richardson (eds.). Ontogeny and Systematics of Fishes. ASIH/Allen Press, Lawrence, pp. 510-522.

Leis, J. M., Olney, J. E., and Okiyama, M. 1997. Introduction to the proceedings of the symposium fish larvae and systematics: ontogeny and relationships. Bull. Mar. Sci. 60: 1-5.

Liu, C. H. 2001. Early osteological development of the yellow tail Seriola dumerili (Pisces: Carangidae). Zool. Stud. 40: 289-298.

McKenney, T.W, Alexander, E. C., and Voss, G. L. 1958. Early development and larval distribution of the carangid fish, Caranx crysos (Mitchill). Bull. Mar. Sci. Gulf Caribbean 8: 167-200.

Miller, J. M., and Sumida B, . Y. 1974. Development of eggs and larvae of Caranx mate (Carangidae). Fish. Bull. 72: 497-514.

Monod, T. 1968. Le complex urophore des poissons téléostéens. Mém. Inst. Fond. Afr Noire 81: 1-705.

Moser, H. G., Richards, W. J., Cohen, D. M., Fahay, M. P., Kendall, A. W. Jr., and Richardson, S. L. (eds.). 1984. Ontogeny and Systematics of Fishes. ASIH/Allen Press, Lawrence.

Nelson, G. J. 1969. Infraorbital bones and their bearing on the phylogeny and geography of osteoglossomorph fishes. Amer. Mus. Nov. 2394: 1-37.

Patterson, C. 1977. Cartilage bones, dermal bones, and membrane bones, or the exoskeleton versus the endoskeleton. In S. M. Andrews, R. S. Miles, and A. D. Walker (eds.). Problems in Vertebrate Evolution. Academic Press, Lawrence, pp. 77-121.

Potthoff, T. 1975. Development and structure of the caudal complex, the vertebral column, and the pterygiophores in the blackfin tuna (Thunnus atlanticus, Pisces, Scombridae). Bull. Mar. Sci. 25: 205-231.

Potthoff, T. 1980. Development and structure of fins and fin supports in dolphin fishes Coryphaena hippurus and Coryphaena equiselis (Coryphaenidae). Fish. Bull. 78: 277-312.

Potthoff, T., Kelley, S., and Javech, J. C. 1986. Cartilage and bone development in scombroid fishes. Fish. Bull. 84: 647-678.

Reed, D. L., Carpenter, K. E., and deGravelle, M. J. 2002. Molecular systematics of the jacks (Perciformes: Carangidae) based on mitochondrial cytochrome b sequences using parsimony, likelihood, and Bayesian approaches. Mol. Phylo. Evol. 23: 513-524.

Rieppel, O., and Kearney, M. 2002. Similarity. Biol. J. Linn. Soc. 75: 59-82. 
Rosenblatt, R. H., and Bell, M. A. 1976. Osteology and relationships of the roosterfish, Nematistius pectoralis Gill. Nat. Hist. Mus. L. A. County Contrib. Sci. 279: 1-23.

Schnakenbeck, W. 1931. Carangidae. Rep. Danish Oceanograph. Exped. 1908-10 Mediterranean and Adjacent Seas. Vol. II. Biol. A. 14: 1-20.

Smith-Vaniz, W. F. 1984. Carangidae: relationships. In H. G. Moser, W. J. Richards, D. M. Cohen, M. P. Fahay, A. W. Kendall Jr., and S. L. Richardson (eds.). Ontogeny and Systematics of Fishes. ASIH/Allen Press, Lawrence, pp. 522-530.

Smith-Vaniz, W. F., and Staiger, J. C. 1973. Comparative revision of Scomberoides, Oligoplites, Parona, and Hypacanthus with comments on the phylogenetic position of Campogramma (Pisces: Carangidae). Proc. Cal. Acad. Sci. 39: 185-256.

Springer, V. G., and Johnson, G. D. 2000. Use and advantage of ethanol solution of alizarin red S dye for staining bone in fishes. Copeia 2000: 300-301.
Starks, E. C. 1911. The osteology and relationships of the fishes belonging to the family Carangidae. Leland Stanford Jr. Univ. Publ. Univ. Ser. 5: 27-49.

Suda, Y. 1996. Osteology and muscular attachments of the Japanese jack mackerel. Trachurus japonicus. Bull. Mar. Sci. 58: 438-493.

Suzuki, K. 1962. Anatomical and taxonomical studies on the carangid fishes of Japan. Rep. Fac. Fish., Prefect. Univ. Mie 4: 43-232.

Tyler, J. C., Johnson, G. D., Nakamura, I., and Collette, B. B. 1989. Morphology of Luvarus imperialis (Luvaridae), with a phylogenetic analysis of the Acanthuroidei (Pisces). Smithsonian Contrib. Zool. 485: $1-78$.

Whitehouse, R. H. 1910. The caudal fin of the Teleostomi. Proc. Zool. Soc. London 1910: 590-627.

Witzell, W. N. 1977. Apolectus niger (family Apolectidae): synonymy and systematics. Matsya 3: 72-82. 